\title{
Integración de prácticas científicas de argumentación, indagación y modelización en un contexto de la vida diaria. Valoraciones de estudiantes de secundaria
}

\author{
Verónica Muñoz-Campos \\ ${ }^{1}$ Didáctica de las Ciencias Experimentales. Universidad de Málaga. Málaga. España \\ ${ }^{2}$ IES Dunas de las Chapas. Marbella, Málaga.España.v.munoz@uma.es \\ Antonio Joaquín Franco-Mariscal \\ Didáctica de las Ciencias Experimentales. Universidad de Málaga. Málaga. España \\ antoniojoaquin.franco@uma.es
}

Ángel Blanco-López

Didáctica de las Ciencias Experimentales.Universidad de Málaga.Málaga.España.ablancol@uma.es

[Recibido: 9 Julio 2019. Revisado: 10 Febrero 2020. Aceptado: 18 Abril 2020]

\begin{abstract}
Resumen: Este trabajo se enmarca en una línea de investigación que pretende la integración del desarrollo de prácticas científicas (argumentación, indagación y modelización) en el contexto de problemas o situaciones de la vida diaria. Se ha diseñado, implementado y evaluado una secuencia de enseñanza-aprendizaje cuya finalidad es el desarrollo de dichas prácticas científicas utilizando como contexto la elaboración de yogur. En concreto, este trabajo analiza las valoraciones sobre esta secuencia de estudiantes de $4^{\circ}$ ESO de dos centros utilizando diferentes instrumentos en distintos momentos de la secuencia. Destaca el alto grado de implicación del alumnado y su percepción de la secuencia como innovadora e interesante. Sin embargo, no todas las tareas son percibidas de igual forma, siendo las relacionadas con indagación y modelización las más y menos valoradas respectivamente. Los resultados obtenidos apuntan a que desde la perspectiva de los estudiantes la integración de estas prácticas científicas es viable, dando lugar a secuencias de enseñanza-aprendizaje que sean de su interés y en las que se impliquen.
\end{abstract}

Palabras clave: integración de enfoques, enseñanza en contexto, prácticas científicas, secuencia de enseñanza-aprendizaje, educación secundaria

Integrating the scientific practices of argumentation, inquiry and modelling in a context of daily life. Secondary students' assessments

Abstract: This paper is part of a research line that aims to integrate the development of scientific practices (argumentation, inquiry and modelling) in the context of problems or situations of daily life. A teaching-learning sequence has been designed, implemented and evaluated of such scientific practices using yogurt production as a context. Specifically, this work analyzes the evaluations of this sequence in high school students from two schools using different instruments at various moments in the teaching sequence. Among the conclusions obtained, the high degree of involvement of the students and their perception of the sequence as innovative and interesting stand out. However, not all scientific practices are perceived in the same way, with inquiry and modelling being the most and least valued practices respectively. The results obtained suggest that the integration of these scientific practices is possible from the perspective of the students, giving rise to teaching-learning sequences that are interesting and in which they are involved.

Keywords: integration of approaches, teaching in context, scientific practices, teaching-learning sequence, secondary education

Para citar este artículo: Muñoz-Campos V, Franco-Mariscal A.J. Y Blanco-López A. (2020) Integración de prácticas científicas de argumentación, indagación y modelización en un contexto de la vida diaria. Valoraciones de estudiantes de secundaria. Revista Eureka sobre Enseñanza y Divulgación de las Ciencias 17(3), 3201. doi: 10.25267/Rev_Eureka_ensen_divulg_cienc.2020.v17.i3.3201

\section{Introducción}


En las últimas décadas se han desarrollado diferentes enfoques de enseñanza de las ciencias adaptados a distintos objetivos y finalidades (Hodson 2014). Entre ellos destacan los enfoques de contextualización (King y Ritchie 2012) y los relacionados con las prácticas científicas de indagación (Bybee 2006; Martin-Hansen 2002), de modelización (Gilbert y Justi 2016) y de argumentación (Erduran y Jiménez-Aleixandre 2008).

Recientes planteamientos sobre las finalidades de la educación científica en torno al desarrollo de prácticas científicas (NRC 2012) demandan enfoques de enseñanza capaces de integrar diversas prácticas científicas y otros aspectos relacionados con la ciencia (conocimientos, actitudes, valores, etc.). La integración de prácticas científicas en el aula de ciencias, tal y cómo vienen planteando diversos autores (p.e. Caamaño 2011) implica la elaboración de secuencias de enseñanza-aprendizaje (en adelante, SEAs) complejas, constituyendo su puesta en práctica y su validación aspectos clave del desarrollo curricular. A los planteamientos utilizados habitualmente para la evaluación de las SEAs (Leach y Scott 2002; Méheut \& Psillos 2004; Psillos y Kariotoglou 2016), centrados en conocer el grado de aprendizaje que alcanzan los estudiantes, es necesario considerar también la visión de los diferentes actores que intervienen en el proceso (estudiantes, profesorado y diseñadores). Desde esta perspectiva, y sobre todo en aquellos casos en los que se llevan a cabo SEAs con nuevos enfoques, las opiniones de los estudiantes son fundamentales y necesarias para conocer su grado de interés e implicación en el proceso (Freire, Faria, Galvao y Reis 2013) y para determinar las fortalezas y debilidades de las SEAs desarrolladas, que permitan realizar procesos de mejora de las mismas. Desde estos planteamientos, la investigación que se presenta en este artículo se centra en analizar las valoraciones de estudiantes sobre una SEA que integra el desarrollo de prácticas científicas (argumentación, indagación y modelización, en adelante AIM) (Blanco, España, Franco y Rodríguez 2018), en el contexto de un problema o situación de la vida diaria (Caamaño 2011) en este caso la elaboración de yogur.

\section{Marco teórico}

Este apartado aborda, en primer lugar, una descripción de las características del enfoque de enseñanza en contexto y de los relativos a las prácticas científicas de AIM, y en segundo lugar un análisis sobre la necesidad de contemplar la evaluación de nuevas SEAs por parte de los estudiantes.

\section{Enseñanza de las ciencias basada en contexto}

En términos generales podemos decir que la enseñanza en contexto se plantea relacionar la ciencia con la vida diaria, actual o futura, de los estudiantes y hacer ver su interés en los ámbitos personal, profesional o social. King (2012) indica, en este sentido, que un enfoque de enseñanza basada en contextos, o contextualizada, consiste en aplicar la ciencia a una situación del mundo real que se usa como estructura central para la enseñanza. Los conceptos científicos se enseñan a medida que son necesarios para comprender mejor la situación planteada.

La finalidad de este enfoque de enseñanza es hacer consciente a los estudiantes la importancia y la utilidad de las ciencias en el mundo contemporáneo entendiendo que de esta forma se facilita el aprendizaje de las ciencias (Caamaño 2005).

El uso de este enfoque aumenta el interés del alumnado sobre aspectos relacionados con la ciencia al construir los conocimientos a través de hechos que suceden en su vida diaria (Gilbert 2006). Chamizo e Izquierdo (2005) consideran que los conceptos científicos surgen de situaciones de la vida real y, por tanto, la ciencia está estrechamente relacionada con contextos cotidianos. Es, por ello, de gran importancia elegir contextos adecuados, que ayuden 
al aprendizaje y además favorezcan la motivación e interés por la ciencia.

\section{Prácticas científicas}

En muchos aspectos de la vida diaria los ciudadanos tienen que tomar decisiones sobre cuestiones socio-científicas como, por ejemplo, las relacionadas con ingeniería, tecnología o alimentación, basándose en sus conocimientos y en la información disponible a través de distintos medios de comunicación (España y Prieto 2009). La necesidad de mejorar la competencia en argumentación es una finalidad primordial de la educación científica. La literatura recoge diferentes definiciones para argumentación en ciencias. Para JiménezAleixandre (2010) "argumentar consiste en ser capaz de evaluar los enunciados en base a las pruebas, es decir, reconocer que las conclusiones y los enunciados deben estar justificados, en otras palabras, sustentados en pruebas". (p. 23). La argumentación ayuda al estudiante a dar respuesta a cuestiones, preguntas y problemas de forma racional, siendo una herramienta que juega un papel esencial en la construcción de explicaciones, modelos y teorías (Toulmin 2003). La argumentación se entiende como actividad social, intelectual y verbal que sirve para justificar o refutar una opinión, y que consiste en hacer declaraciones teniendo en cuenta al receptor y la finalidad con la cual se emiten (Sanmartí 2003). Para argumentar hace faltar elegir entre diferentes opciones o explicaciones y razonar los criterios que permiten evaluar como más adecuada la opción elegida. En resumen, la importancia de la argumentación en la enseñanza de las ciencias se ha puesto de relevancia, ya que la educación científica implica tanto aprender ciencia, en lo que concierne a contenidos epistemológicos, y aprender a hacer ciencia, que considera necesario desarrollar las capacidades de indagación propias de la ciencia, entre las que se encuentra el desarrollo y evaluación de los argumentos (Duschl y Osborne 2002). Para ello, deben diseñarse y proponerse actividades y estrategias en contextos adecuados que permitan poner al alumnado en disposición de comprender y usar el discurso y los modelos científicos, al tiempo que pueden manejar con sentido crítico situaciones relacionadas con las ciencias que les permitan dar una solución y establecer un debate sobre problemas auténticos (JiménezAleixandre 2002), es decir, problemas interesantes y significativos para los estudiantes.

El uso del término indagación o inquiry (en inglés) suele tener diversas acepciones en el ámbito educativo (Barrow 2006). En unos casos se entiende como una capacidad cognitiva, la de indagar e investigar científicamente, que los estudiantes tienen que desarrollar. En otros, se refiere a la comprensión de los métodos usados por los científicos, es decir a la naturaleza de la indagación científica. Una tercera acepción hace referencia a diversas estrategias didácticas que se pueden utilizar para que los estudiantes desarrollen capacidades de indagación, aprendan sobre la indagación científica o para comprender y aprender conceptos científicos. En definitiva, la indagación puede entenderse como un proceso complejo de construcción de significado y modelos conceptuales, en el que se formulan cuestiones, se diseñan procedimientos para encontrar respuestas, se comprende y construye nuevo conocimiento que se comunica a otros, y se aplica el conocimiento de forma productiva a situaciones no familiares. Entendida de esta forma, la indagación incluye muchas de las prácticas científicas recogidas en el marco K-12 (NRC 2012) que se deberían incluir en la enseñanza de las ciencias entre preescolar y el final de secundaria (grado 12). Existe una gran diversidad de enfoques metodológicos de indagación en el aula (Rönnebeck, Bernholt y Ropohl 2016). Bevins y Price (2016) propusieron un modelo que incluye aspectos conceptuales, procedimentales, epistemológicos y personales y consideran que el proceso de enseñanza-aprendizaje a través de esta práctica facilita la adquisición de conocimientos científicos. La indagación debe estar influenciada por motivos afectivos y motivadores para los estudiantes que les acerquen de forma positiva los procesos científicos que ocurren en su día a día.

Actualmente la modelización se considera una parte esencial de la actividad científica (Justi 
2006) y la enseñanza por modelización, o los enfoques de enseñanza-aprendizaje en torno a modelos, constituyen una de las líneas más fecundas de investigación en didáctica de las ciencias (Gilbert y Justi 2016). La competencia de modelización podría entenderse como un conjunto integrado de conocimientos, metaconocimientos, destrezas y valores epistémicos necesarios para llevar a cabo la tarea de modelizar en su dimensión amplia, no solo con el propósito de aprender los modelos de la ciencia escolar, sino también de trabajar con ellos, elaborarlos y revisarlos, así como hablar y opinar acerca de los mismos, entendiendo su valor, su utilidad, su carácter aproximativo y cambiante y, también, sus limitaciones (Oliva 2019). Los enfoques de modelización parten de que los modelos son el núcleo central en torno al que se genera el conocimiento, tanto en la ciencia como en el alumnado. Schwarz (2009) propone cuatro tipos de tareas en la práctica de modelización de menor a mayor complejidad: (a) construir modelos consistentes con evidencia admisible y teorías sobre cómo ilustrar, explicar y predecir fenómenos, (b) utilizar modelos para ilustrar, explicar y predecir fenómenos, (c) comparar y evaluar la capacidad de diferentes modelos tanto para representar adecuadamente y capturar patrones en fenómenos como para predecir nuevos, y (d) revisar modelos de manera que se incremente su potencial explicativo o predictivo, considerando pruebas adicionales o nuevos aspectos en los mismos fenómenos o en otros similares.

\section{Diseño y evaluación de SEAs}

El diseño de SEAs es considerado hoy día un campo privilegiado para la investigación, la innovación y la formación del profesorado (Couso 2011). El término SEA se utiliza para designar a una propuesta didáctica corta en el tiempo y centrada en el aprendizaje de tópicos concretos del currículum escolar de ciencia. Este campo surge como intento de acercar la investigación y la práctica docente y una de sus características distintivas es su carácter dual, ya que conlleva a la vez actividades de investigación y desarrollo dirigidas a establecer una estrecha vinculación entre la enseñanza y el aprendizaje de un tema en particular. El proceso de diseño y validación de una SEA es una actividad de investigación en la práctica educativa y un producto, una unidad curricular concreta, que incluye actividades de enseñanza-aprendizaje bien investigadas empíricamente y adaptadas a la capacidad de razonamiento de los estudiantes. A veces, las guías para la utilización de las SEAs también incluyen las reacciones esperadas de los estudiantes (Méheut \& Psillos 2004).

A lo largo de las dos últimas décadas se han ido proponiendo diferentes modelos para diseñar SEAs (Couso 2011). Duit (2006) distingue dos tradiciones específicas en este sentido, que denomina pedagógica y empírica respectivamente. En la tradición pedagógica el foco de atención se centra en la práctica docente y los problemas relacionados con los contenidos científicos. En la tradición empírica las SEAs se orientan hacia las necesidades de los estudiantes y la mejora en los entornos de aprendizaje, prestando menos atención a los contenidos científicos. Este autor señala que el progreso en la comprensión y el aprendizaje de las ciencias solo será posible si existe cierto equilibrio entre estas dos tradiciones.

Una cuestión importante en este ámbito de investigación, además del diseño, lo constituye los enfoques y los procesos de evaluación de las SEAs que, en términos generales, consisten en obtener información y pautas para hacer que converjan, en lo posible lo que está previsto, lo que se implementa y lo que se alcanza con dichas SEAs. Estos procesos proporcionan validez empírica a las SEAs al considerar las reacciones de los estudiantes y los profesores y su aplicabilidad contextual (Psillos y Kariotoglou 2016).

Al igual que en el diseño, en los aspectos de validación también cabría identificar las dos tradiciones citadas. En el caso de la tradición pedagógica el foco de la evaluación de la efectividad de una SEA se pone fundamentalmente en el aprendizaje de los estudiantes, bien comparando los estados finales e iniciales (como se hace en las metodologías pre/post-test) o 
estudiando el desarrollo del aprendizaje de los estudiantes (itinerarios de progresión) durante el proceso de enseñanza-aprendizaje (Leach y Scott 2002; Méheut y Psillos 2004). Desde la tradición empírica este enfoque se ha considerado incompleto ya que no tiene en cuenta la multiplicidad de factores relativos a la ecología del aprendizaje, tales como la participación y colaboración de los estudiantes (Psillos y Kariotoglou 2016). En este sentido, Leach y Scott (2002) consideran que aunque los métodos de evaluación antes citados son válidos, ya que el objetivo principal de las SEAs es promover el aprendizaje de los estudiantes, informan muy poco sobre las causas de los aprendizajes obtenidos y, sobre todo, de los no alcanzados, ya que no se recopilan datos sobre cómo se llevó a cabo la enseñanza. Como indican estos autores la afirmación de que los aprendizajes alcanzados por los estudiantes se puedan atribuir a las actividades que constituyen la SEA en sí mismas más que a la forma particular en que son desarrolladas en el aula, sigue siendo una cuestión problemática. Leach y Scott (2002) centran su atención en el papel del profesorado que implementa las SEAs, especialmente en cómo interpretan las actividades de enseñanza incluidas en ellas y las ponen en práctica en sus clases.

Desde la tradición empírica, las valoraciones de los estudiantes sobre el diseño y desarrollo de SEAs también pueden ser de gran utilidad para analizar las posibles causas de las diferencias entre los aprendizajes obtenidos y los deseados. A pesar de ello, parece ser una línea de trabajo poco explorada. Freire et al. (2013) argumentan la necesidad de conocer las opiniones de los estudiantes si se pretende que las clases de ciencias sean más atractivas y relevantes para los estudiantes y, de esta forma, aumentar su interés por la ciencia escolar. Esto puede ser de especial interés en los casos de SEAs en las que se pretende integrar propuestas teóricas prometedoras, como las de integración de diferentes enfoques didácticos (Caamaño 2011), pero de las que todavía no se disponen de suficientes datos empíricos.

Partiendo de que las evaluaciones de las SEAs requieren la combinación de diferentes enfoques, ya mencionados, en esta investigación nos centramos exclusivamente en la perspectiva de los estudiantes, analizando las valoraciones que realizan en diferentes momentos del desarrollo de una SEA centrada en la integración de la argumentación, indagación y modelización en el contexto del estudio de la elaboración de yogur y su influencia en la salud.

\section{Preguntas de investigación}

Este trabajo se plantea tres preguntas:

P1: ¿Qué valoraciones realizan estudiantes de $4^{\circ}$ ESO sobre una SEA que integra prácticas científicas de AIM en el contexto del consumo de yogur?

P2: ¿Qué valoraciones realizan los estudiantes sobre cada una de las tareas planteadas para cada práctica científica?

P3: ¿Existen diferencias entre las valoraciones de estudiantes de $4^{\circ}$ ESO de dos centros diferentes?

\section{Secuencia de enseñanza-aprendizaje}

La SEA titulada ¿Es necesario tomar yogur? está centrada en un ámbito relevante de la vida diaria -alimentación y salud- (Fensham 2009), y en concreto en aspectos relacionados con la elaboración de yogur y su influencia en la salud; considerando que es un producto muy cotidiano para los estudiantes y que, sin embargo, no aparece entre los temas más utilizados en la enseñanza de las ciencias (Jiménez-Liso, López-Gay y Márquez 2010). Además, su 
tratamiento ofrece oportunidades para abordar diferentes aspectos de la modelización y la indagación (Muñoz, Blanco y Franco 2015) y ayuda a los estudiantes a aprender un modelo importante en la ciencia escolar como es el de las reacciones químicas y, en concreto, el de fermentación (Moreno y López 2013).

La SEA se desarrolla a través de varios interrogantes organizadores que abordan el yogur desde diferentes perspectivas (su consumo, su composición, su elaboración, sus beneficios o perjuicios para la salud) y que permiten trabajar diferentes aspectos de las prácticas científicas (Figura 1).

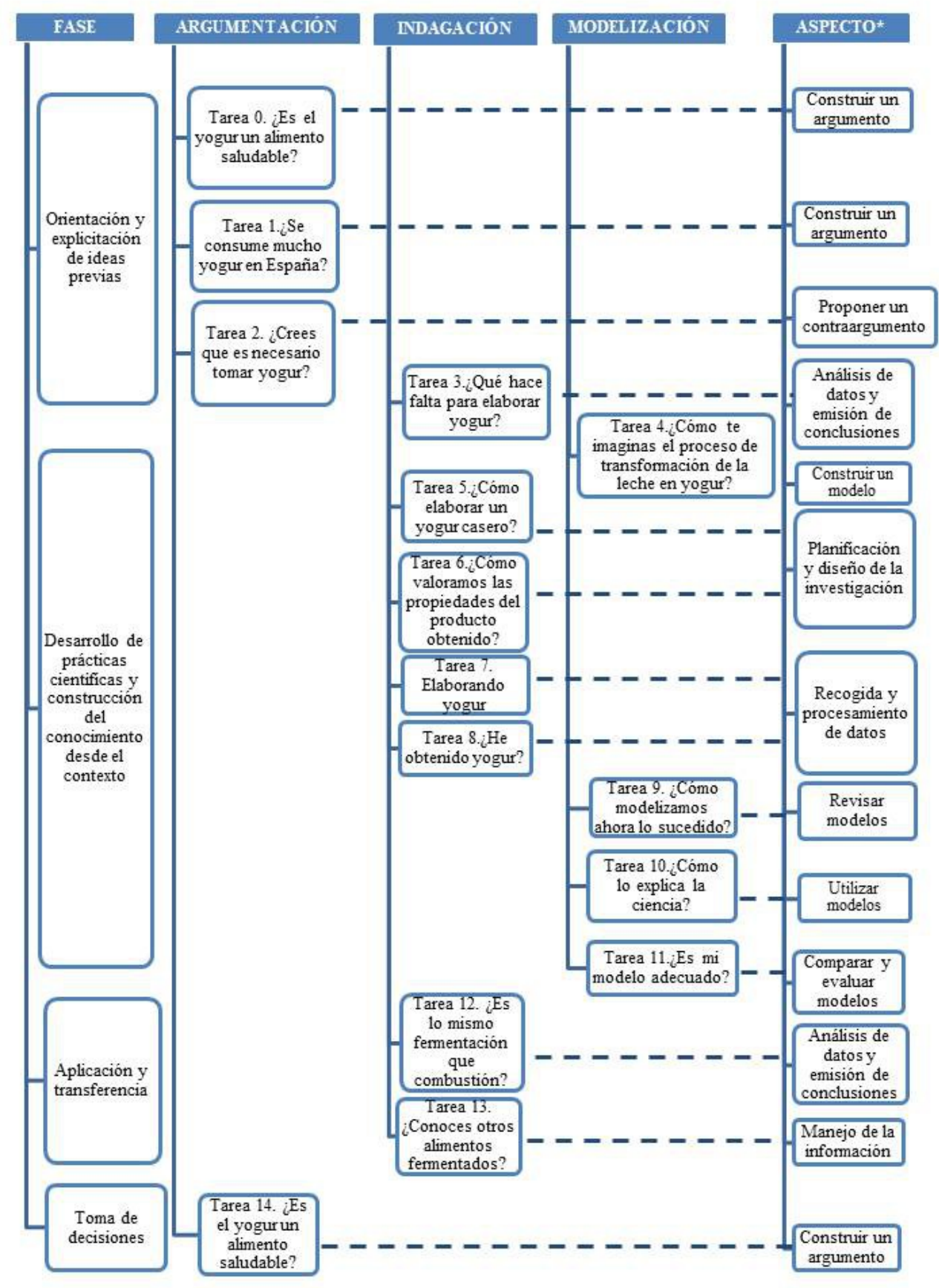

Figura 1. Tareas de la SEA en cada fase y su relación con las prácticas científicas 
Las respuestas que los estudiantes van dando a cada uno de los interrogantes no sólo permiten que adquieran conocimientos sobre el proceso de transformación de la leche en yogur (fermentación), sino también que al final de la SEA sean capaces de tomar decisiones argumentadas relacionadas con hábitos de vida saludable.

Los aspectos de cada práctica científica que se trabajan en la SEA están recogidos como tales en esquemas bien asentados en la literatura como son la argumentación de Osborne et al. (2016), la indagación de Franco-Mariscal (2015), y la modelización de Schwarz et al. (2009). Esto no quiere decir que en la SEA se aborden las tres propuestas de forma completa sino solo aquellos aspectos que desde el punto vista didáctico se consideran necesarios para alcanzar las finalidades que pretende la SEA.

La argumentación se aborda, principalmente, de forma escrita con la finalidad de ayudar a los estudiantes a valorar de forma crítica y racional algunas afirmaciones que se plantean en los medios de comunicación y en la publicidad sobre los beneficios alimenticios del yogur. En concreto las tareas de argumentación incluían construir un argumento y proponer contraargumentos, recogidos en los distintos aspectos del esquema de Osborne et al. (2016) con distintos niveles de dificultad, y que diferencia dos dimensiones, una relacionada con la construcción de un argumento, y otra con la crítica y reflexión de argumentos.

El uso de la indagación en esta SEA ofrece oportunidades para diseñar y elaborar yogur en el aula y comprender de primera mano cómo tiene lugar el proceso, dando respuesta a las siguientes preguntas ¿cómo elaborar un yogur casero? y ¿qué factores se deben tener en cuenta para hacerlo? Las tareas involucradas en la indagación requerían que los estudiantes manejen información, planifiquen y diseñen la investigación, recojan y analicen datos, emitan conclusiones y comuniquen resultados (Franco-Mariscal 2015).

La modelización pretende, en esta SEA, ayudar a conocer cómo ocurre a nivel microscópico la transformación de leche en yogur, a través de la elaboración de diferentes modelos que el alumno debe ir mejorando hasta acercarse al modelo escolar. En concreto, los estudiantes tienen la oportunidad durante la SEA de: 1) construir modelos consistentes con evidencia admisible, 2) utilizar estos modelos para ilustrar, explicar y predecir fenómenos, 3) comparar y evaluar diferentes modelos tanto para representar adecuadamente y capturar patrones en fenómenos como para predecir nuevos, y 4) revisar modelos de forma que se incremente su potencial explicativo o predictivo, considerando pruebas adicionales o nuevos aspectos en los mismos fenómenos o en otros similares (Schwarz et al. 2009). En este sentido, las tareas de indagación ayudan a los estudiantes a mejorar sus modelos iniciales.

Para la implementación de la SEA se utilizaron 9 sesiones de 1 hora de duración. Las tareas relacionadas con argumentación y modelización se impartieron en el aula mientras que las que contemplaban la práctica de indagación se abordaron en el laboratorio. El desarrollo de las tareas en el aula seguían un patrón similar, consistente en trabajo de forma individual que los alumnos recogían en su cuaderno de trabajo (elaborado ex profeso para esta SEA) y posteriormente una puesta en común en gran grupo.

A continuación se muestra un ejemplo de tarea de cada práctica científica y cómo se implementó en el aula.

Una tarea de argumentación (Tarea 14, Figura 2) planteó el interrogante ¿es el yogur un alimento saludable? Consistió en que los alumnos leyeran y debatieran sobre el contenido de dos artículos ${ }^{1}$ con información contradictoria sobre el yogur como alimento saludable. A partir de su lectura, debían extraer la idea principal de cada texto, las evidencias que aportan para apoyar sus ideas, y, argumentar si es o no necesario tomar yogur.

\footnotetext{
${ }^{1}$ Artículo 1: https://bit.ly/2To1F32; Artículo 2: https://bit.ly/1Apqjp0
} 
a) ¿Cuál es la idea principal de cada uno de los textos?

Texto A: ES beneficioso tomar yogur ya que es in alimentas rico en calcio, easforo, vitaminas, etc. que previenen la desmineralización de wesos y dientes, hideatan el aveepo y eqpilibean nuestra flosa intestinal 4 apda a nestas defensas. Texto B: Que na es necesario tomar yogur ya que por estudios que se man hecho con persoras aie tomaban yogre a diakio no se ha visto ninguna mejoea de calidad de Sawd.

b) ¿Qué evidencias se ponen de manifiesto en cada texto para apoyar sus ideas?

Texto A: Su composición, es decir, que esta' formado por sustancias sencillas de absor ver; tienen calcio, fósfoeo y vitaminas: 4 contienen peobióticos. Re 6 que sano, ya ave mejora nuestro sistema inmunológico.

Texto B: Para apayarlo hablan de Su investigacion, en la que hicieron un estodio con 4.445 persanas maypes de edad que comirebon yeque a diario durante 3 años $y$ medio, y cespuels de realizar les un test cientifico se cemostbó qe comer yeque no prodvcía ninguna mejora en la calidad de vida Relacionada car la Sawd.

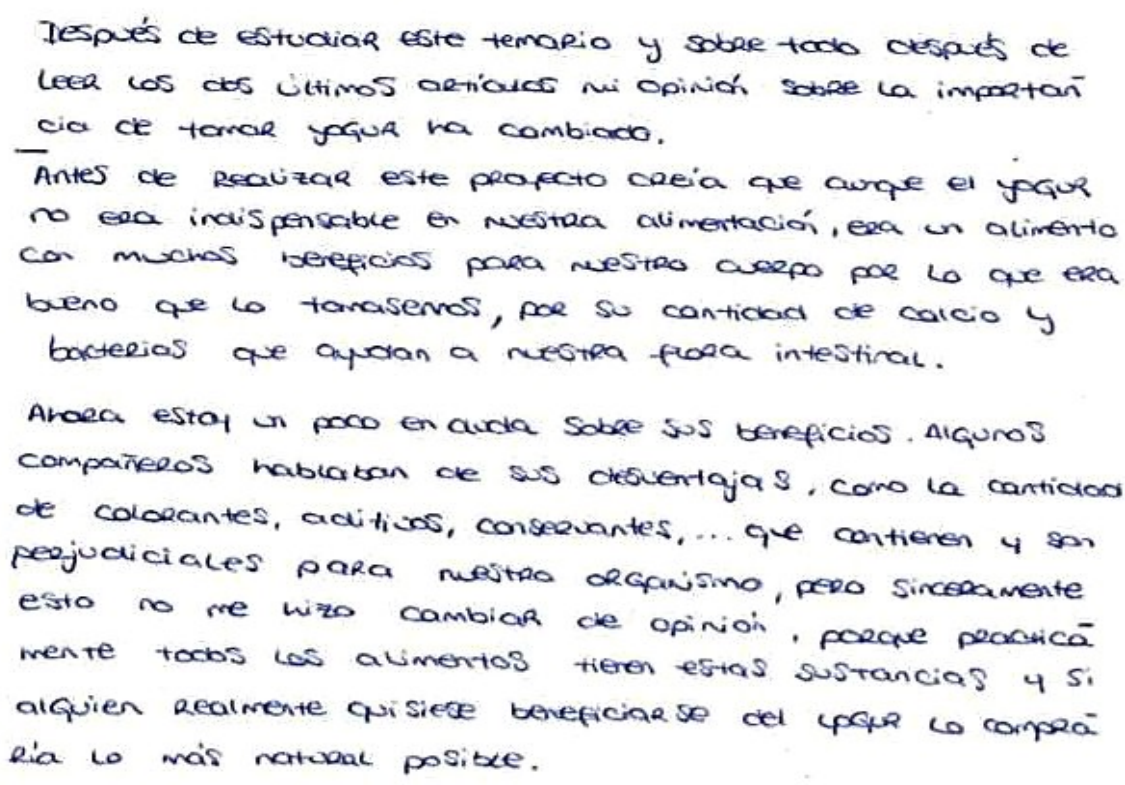

Figura 2. Tarea 14 desarrollada en el cuaderno del estudiante 
A modo de ejemplo, la tarea 5 (Figura 3) presentada a través del interrogante ¿cómo elaborar un yogur casero?, consistió en que los estudiantes diseñaran un experimento para elaborar yogur en clase. Para ello, se demandó establecer las variables implicadas, como la cantidad y tipo de leche, cantidad de fermentos, etc., y a partir de ellas diseñar varios experimentos que se podrían realizar.

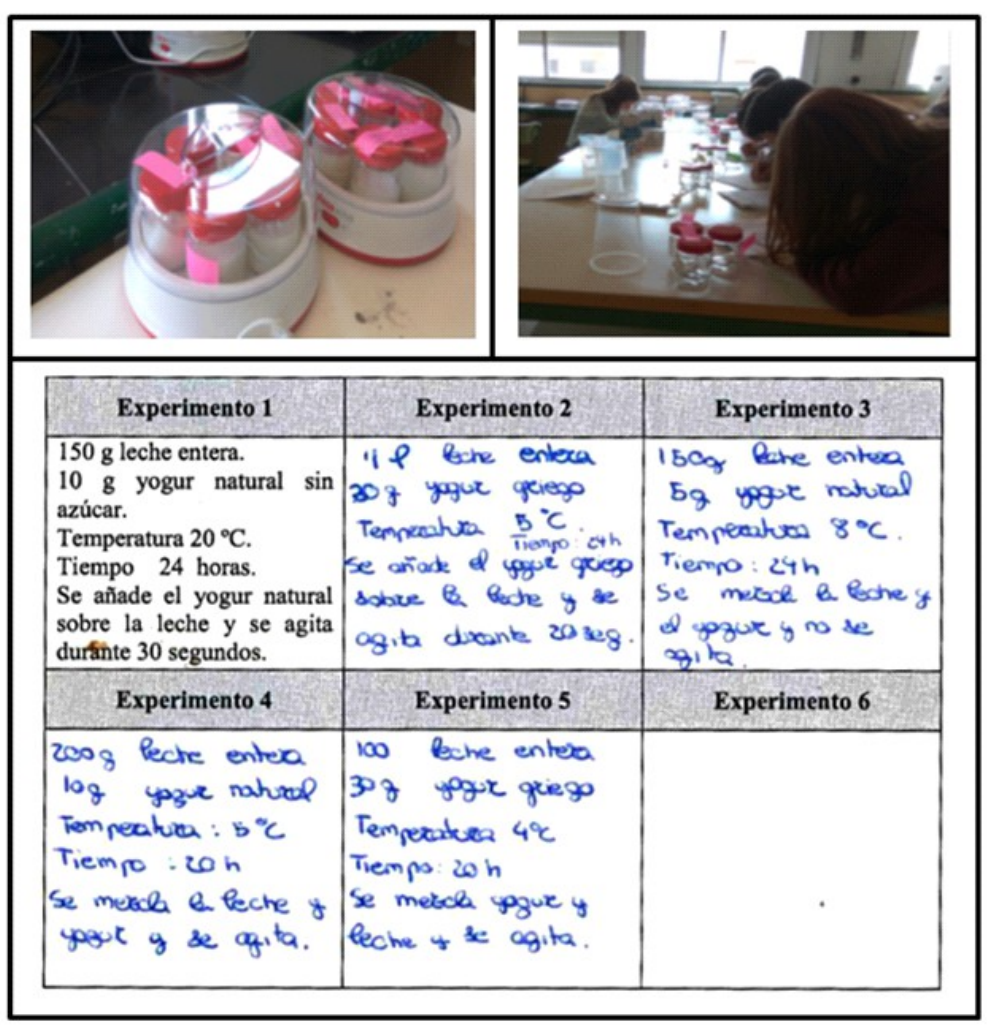

Figura 3. Desarrollo de la tarea 5 en el aula

Un ejemplo de actividad de modelización es la tarea 4, ¿cómo te imaginas el proceso de transformación de la leche en yogur?, en la que debían proponer un modelo sobre cómo se imaginaban que las bacterias transforman el azúcar de la leche en ácido. El modelo debía incluir un dibujo y una explicación. Una vez propuesto, se pidió justificar las variables que se debían controlar en la elaboración de yogur. Finalmente, se realizó una puesta en común para establecer opiniones y diferencias entre los distintos modelos propuestos (Figura 4). 


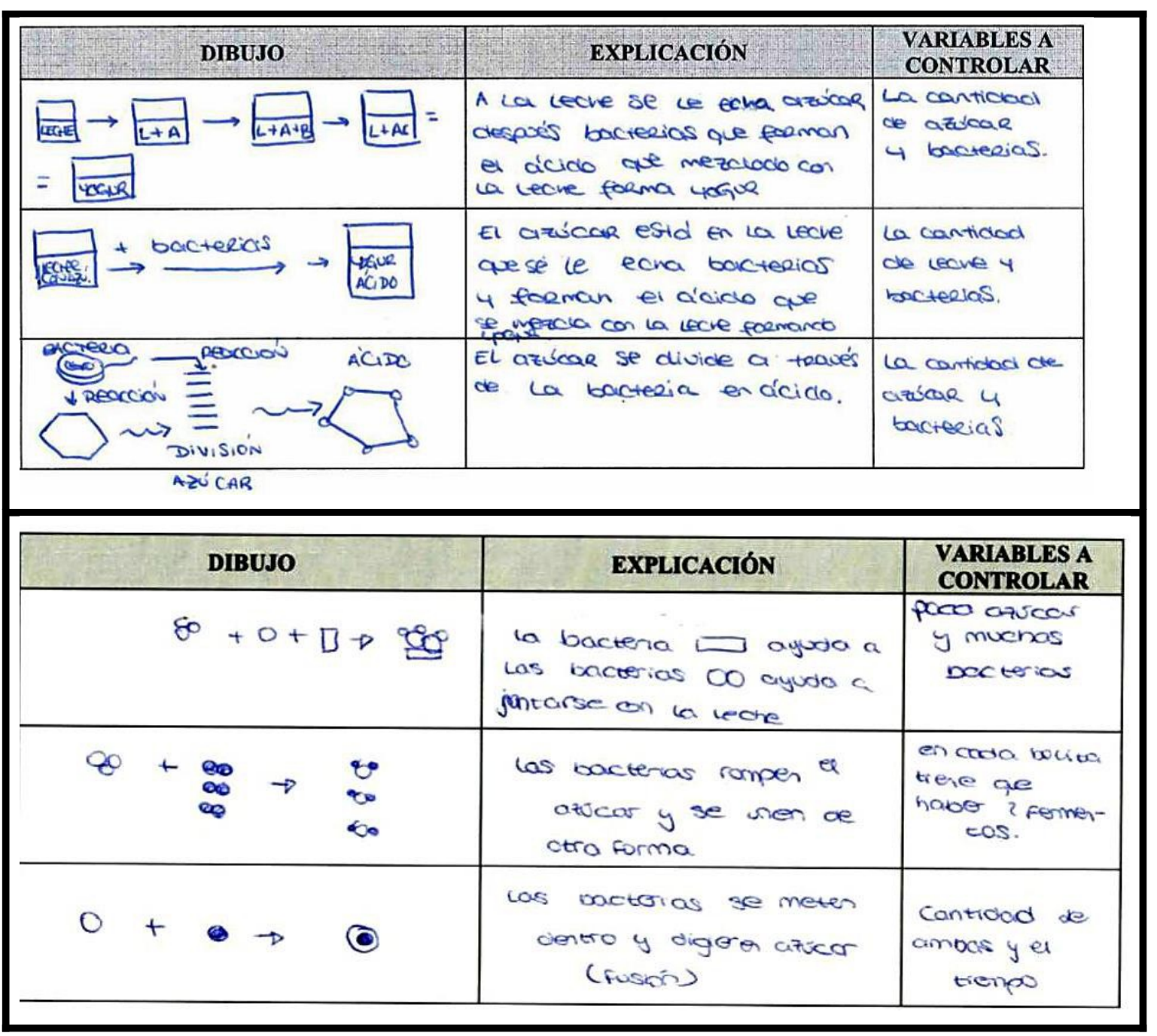

Figura 4. Ejemplos de modelos propuestos para la transformación de leche en yogur en la tarea 4

\section{Metodología de la investigación}

\section{Participantes}

Esta SEA se implementó con 25 estudiantes pertenecientes a dos institutos de secundaria de Málaga, uno en una ciudad costera de la provincia (grupo A, N=14) y otro en la capital (grupo $\mathrm{B}, \mathrm{N}=11) .13$ eran chicas y 12 chicos, y sus edades estaban comprendidas entre 14 y 17 años. Todos ellos cursaban la asignatura optativa de Física y Química de $4^{\circ}$ ESO y en sus preferencias manifestaban estudiar en el futuro opciones de ciencias. El grupo A no había recibido formación sobre ninguna de estas tres prácticas científicas, lo que suele ser habitual en la enseñanza de la física y química de la zona a la que pertenecen los centros participantes. Sin embargo, el grupo B ya había participado en proyectos relacionados con indagación aunque no había recibido enseñanza sobre argumentación y modelización.

La SEA fue desarrollada en cada centro educativo por un docente diferente. Ambos docentes (los dos primeros autores de este trabajo) son investigadores en didáctica de las ciencias experimentales y diseñaron de forma conjunta la SEA. Asimismo, realizaron un seguimiento de la implementación de forma coordinada en los dos centros, para que la puesta en práctica se realizara en idénticas condiciones. 


\section{Instrumentos de recogida de datos}

Los instrumentos se diseñaron para recoger información sobre las valoraciones del alumnado, de su percepción global de la SEA y sobre las tareas organizadas en torno a las tres prácticas científicas contempladas. Se emplearon 3 instrumentos:

El instrumento 1 (Anexo I) consistía en fichas de valoración de las distintas tareas en las que debían indicar qué habían aprendido, los aspectos que a su juicio consideraban mejor y peor de la tarea desarrollada, y otorgarle una puntuación de 0 a 10. Los estudiantes cumplimentaron 9 fichas, una al final de cada sesión, que incluían las 14 tareas de las SEA (Figura 1) ya que algunas de ellas englobaban dos tareas relacionadas con la misma práctica científica realizadas en la misma sesión. Este instrumento permitía realizar una monitorización y seguimiento de las impresiones in situ que los estudiantes manifestaron inmediatamente después de realizar cada tarea.

El instrumento 2 (Anexo II) consta de 8 ítems que demandan aspectos específicos de la SEA (objetivos, enfoques, actividades, implicación del alumnado, grado de aprendizaje, etc.). Los alumnos debían responder cada ítem marcando su percepción en una escala Likert de 4 opciones de menor a mayor acuerdo con el enunciado y justificar su respuesta.

El instrumento 3, el diario de los profesores investigadores, utilizado por cada profesor/a de forma independiente, se empleó para registrar el progreso de cada sesión y las discusiones que tuvieron lugar en ellas, basadas en notas de campo, y las reflexiones sobre el proceso de enseñanza-aprendizaje que estaba teniendo lugar.

La combinación de estos 3 instrumentos ha permitido integrar diferentes percepciones sobre el desarrollo de la SEA en el aula, al posibilitar la triangulación de datos y otorgar mayor validez y fiabilidad a los resultados obtenidos (Cohen, Manion y Morrison 2007). Así, las valoraciones realizadas durante el desarrollo de la SEA (instrumento 1), se pueden confrontar con aquellas otras más sosegadas y globales realizadas después de finalizarla (instrumento 2), y todas ellas a su vez con la percepción de los profesores investigadores (instrumento 3).

\section{Análisis de datos}

El análisis de datos se llevó a cabo en dos fases:

Fase 1: Valoración global de la SEA utilizando los datos obtenidos a partir de los ítems 1, 2, 3, $4,5,7$ y 8 del instrumento 2 .

Fase 2: Valoración de las tareas relativas a las prácticas científicas partiendo de las puntuaciones que otorgan a cada tarea durante el desarrollo de la SEA (instrumento 1), del ítem 6 del instrumento 2 y del instrumento 3 .

Para cada fase se llevó a cabo un análisis de toda la muestra global y también de cada uno de los grupos. Aunque la SEA se llevó a cabo en los dos grupos de forma similar, se consideró importante este análisis ya que cada grupo tenía, como se ha indicado antes, perfiles diferentes con respecto a su familiaridad con las prácticas científicas.

Para obtener la puntuación otorgada a cada práctica científica se calculó el valor medio de las puntuaciones dadas a las tareas y a los objetivos relacionados con cada práctica. Para el análisis estadístico se utilizó el software SPSS 21.0, calculándose como estadísticos descriptivos las medias y las desviaciones típicas para cada una de las variables definidas. Debido al tamaño de la muestra y a la distribución de los datos, se utilizaron pruebas no paramétricas para comprobar si existían diferencias significativas entre grupos. Se empleó la prueba U de MannWhitney para dos muestras independientes y la prueba de rangos con signo de Wilcoxon para muestras relacionadas. Para una mejor comprensión de los resultados, el estudio cuantitativo 
se complementó con citas textuales del alumnado codificadas con una letra (A ó B) para el grupo y dos dígitos para identificar al alumno/a.

\section{Resultados y discusión}

\section{Valoración global de la SEA}

La tabla 1 recoge los resultados para el conjunto de estudiantes en cada ítem del instrumento 2 relacionado con la valoración global de la SEA. Cabe destacar que apenas se encontraron diferencias entre los dos casos.

Tabla 1. Resultados para el total de estudiantes de los ítems del instrumento 2 que valoraban la SEA

\begin{tabular}{|c|c|c|c|}
\hline \multicolumn{2}{|c|}{ Prácticamente igual a la de siempre: 2} & \multicolumn{2}{|c|}{ Han cambiado muchas cosas: 10} \\
\hline \multicolumn{2}{|c|}{$\begin{array}{l}\text { Han cambiado algunas cosas (actividades, forma de relacionarnos } \\
\text { en las clases, actuación del profesor): } 4\end{array}$} & \multicolumn{2}{|c|}{ Ha sido totalmente nueva: 9} \\
\hline \multicolumn{4}{|c|}{ Ítem 2. El tema que se ha tratado en la SEA te ha parecido: } \\
\hline Muy poco interesante: 0 & Poco interesante: 0 & Interesante: 19 & Muy interesante: 6 \\
\hline \multicolumn{4}{|c|}{ Item 3. En general, durante esta SEA en las clases te has sentido: } \\
\hline Muy poco implicado: 0 & Poco implicado: 1 & Implicado: 20 & Muy implicado: 4 \\
\hline \multicolumn{4}{|c|}{ Ítem 4. Sobre el tema has aprendido: } \\
\hline Muy poco: 0 & Poco: 1 & Algo: 6 & Mucho: 18 \\
\hline \multicolumn{4}{|c|}{ İtem 5. En general durante esta SEA, sobre ciencia he aprendido: } \\
\hline Muy poco: 0 & Poco: 0 & Algo: 18 & Mucho: 7 \\
\hline \multicolumn{4}{|c|}{$\begin{array}{l}\text { Ittem 7. ¿Te gustaría que la forma de trabajar en las clases de esta asignatura fuera siempre tal y como se ha hecho en esta } \\
\text { SEA? }\end{array}$} \\
\hline Sí: 16 & No: 0 & \multicolumn{2}{|l|}{ Depende: 9} \\
\hline \multicolumn{4}{|c|}{ Ítem 8. ¿Cuándo has aprendido más: en esta SEA o en las anteriores de esta asignatura? } \\
\hline En ésta: 15 & En las anteriores: 2 & \multicolumn{2}{|l|}{ En ambas: 8} \\
\hline
\end{tabular}

El análisis de las respuestas reveló que la mayoría de los estudiantes valoraron la metodología de la SEA como totalmente nueva porque habían cambiado muchas cosas (ítem 1) (20/25 estudiantes), encontrándola todos interesante o muy interesante (ítem 2), expresándolo de esta forma:

"Las clases han sido muy entretenidas e interactivas" (A03)

"Me parece interesante porque hemos tratado reacciones químicas en un proceso cotidiano como la alimentación” (A05)

"Ha sido algo que no habíamos visto antes en clase" (B08)

La gran mayoría de los estudiantes también indicaron que se sintieron implicados o muy implicados (24/25) durante la SEA (ítem 3). Muchos de ellos lo relacionaban con el enfoque de enseñanza empleado:

"Este método de trabajo ha hecho que en cada ejercicio teníamos que valernos de nuestros conocimientos e intuición, no como se hace normalmente. Después de cada actividad hemos argumentado nuestras respuestas” (B11)

"Me esfuerzo más, tenía que hacer diseño de modelos, etc. He hablado y propuesto mis modelos" (A04)

"Al tener que razonar en casi todas las actividades te implicas más" (B09) 
Respecto al aprendizaje, 18 estudiantes indicaron que habían aprendido mucho sobre el tema de la transformación de leche en yogur (ítem 4), señalando el mismo número que había adquirido algunos conocimientos científicos nuevos (ítem 5). Asimismo, 16 mencionaron que habían aprendido más en esta SEA que en las anteriores (item 7):

"De esta forma me cuesta menos entender las cosas" (A05)

"El método de estudio es más eficaz" (A13)

"He aprendido más conocimientos generales en los temas anteriores, pero con esta forma de trabajo me voy a acordar siempre de lo aprendido” (B09)

16 estudiantes indicaron que le gustaría continuar trabajando de este modo en el aula (ítem 8), apoyándose en comentarios como "es más divertido y se aprende más" (A02) o "las clases son más amenas y se hacen más cortas" (B07). No obstante, 9 dudaban sobre utilizar esta metodología con otro tipo de contenidos, argumentándolo como "depende del tema" (A10), "la forma de trabajar es muy entretenida y dinámica, pero creo que para ciertos temas de trabajo este método no funciona" (B06) o "algunas veces es más fácil hacer los ejercicios de forma individual" (A03).

Se han estudiado posibles diferencias estadísticamente significativas entre grupos (A y B) (Tabla 2) de las valoraciones numéricas dadas a los ítems 1, 2, 3, 4 y 5, del instrumento 2 formulados mediante escala Likert con 4 niveles.

Tabla 2. Estadísticos descriptivos de las respuestas obtenidas por los estudiantes en los ítems del instrumento 2

\begin{tabular}{cccccc}
\hline & & \multicolumn{5}{c}{ Diferencia entre grupos } \\
\hline Ítem & Media & Varianza & U de Mann-Whitney & $\mathbf{Z}$ & $\mathbf{p}$ \\
\hline 1 & 3.13 & 0.723 & 55.500 & -1.020 & 0.308 \\
2 & 3.13 & 0.375 & 61.500 & -0.803 & 0.422 \\
3 & 3.00 & 0.348 & 56.000 & -1.303 & 0.193 \\
4 & 3.58 & 0.341 & 52.500 & -1.327 & 0.185 \\
5 & 3.29 & 0.216 & 66.000 & -0.440 & 0.660 \\
\hline
\end{tabular}

Los resultados obtenidos muestran en estos ítems que los estudiantes valoran los distintos aspectos de la SEA de forma muy positiva, con puntuaciones medias superiores a 3 . No existen diferencias estadísticamente significativas entre las puntuaciones dadas a cada ítem por cada uno de los grupos. En este sentido, puede indicarse que las valoraciones globales son similares en toda la muestra.

También se han analizado las posibles relaciones entre las puntuaciones otorgadas a distintos ítems. Así, se han encontrado diferencias significativas, que indica que los estudiantes consideran que han aprendido más sobre el tema tratado (elaboración del yogur, ítem 4) que sobre ciencias (ítem 5). Esta diferencia aparece en la muestra global $(Z=-2.111 ; p=0.035)$ y para el grupo A ( $\mathrm{Z}=-2.236$; $\mathrm{p}=0.025)$, y no así en el grupo $\mathrm{B}$. El hecho de enseñar las ciencias en un contexto de la vida diaria parece que hace que los estudiantes muestren una menor valoración de lo que están aprendiendo. Asimismo, también aparecen diferencias estadísticamente significativas globales $(\mathrm{Z}=-2.392 ; \mathrm{p}=0.016)$, que muestran una relación directa entre el grado de novedad que los estudiantes otorgan a la SEA (ítem 1) y el grado de aprendizaje adquirido sobre el tema tratado (ítem 4). 


\section{Valoración de las prácticas científicas}

Para determinar qué práctica científica les resultó más interesante se analizaron las puntuaciones dadas a cada tarea en las fichas de valoración cumplimentada inmediatamente después de cada sesión. La figura 5 presenta las puntuaciones medias en cada tarea, agrupadas por prácticas científicas para cada grupo y para el total de alumnos.

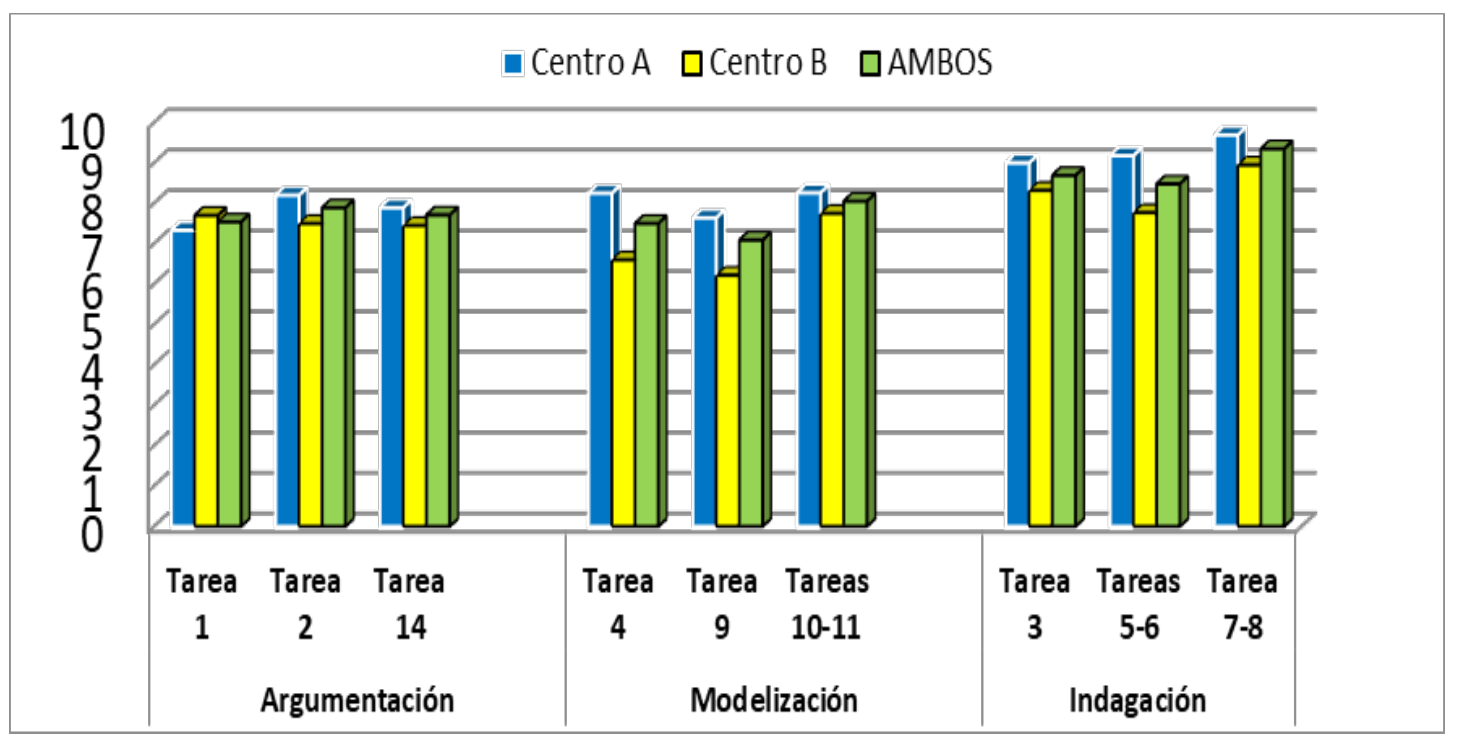

Figura 5. Puntuaciones medias otorgadas por los estudiantes a cada tarea en las fichas de valoración

En primer lugar, se aprecia que, salvo para la tarea 1 " ¿Se consume mucho yogur en España?”, los estudiantes del grupo A valoraron siempre las tareas con puntuaciones mayores que los del grupo B. A pesar de ello, estas puntuaciones no fueron muy diferentes dentro del mismo enfoque, excepto para la modelización donde se encontró la mayor diferencia de puntuación en las tareas 4 y 9.

A partir de las puntuaciones de las tareas asociadas a cada práctica científica se realizó un valor medio (Figura 6). Como se observa, a pesar de que las tres prácticas reciben buenas calificaciones, no todas son igualmente valoradas. Así, la indagación fue la mejor valorada en todos los casos, con una media de 8.84 puntos, que en el grupo A llegó a superar la calificación de 9 (9.29). A continuación, le siguió la argumentación (7.71 puntos), siendo la modelización la práctica peor valorada (7.55 puntos).

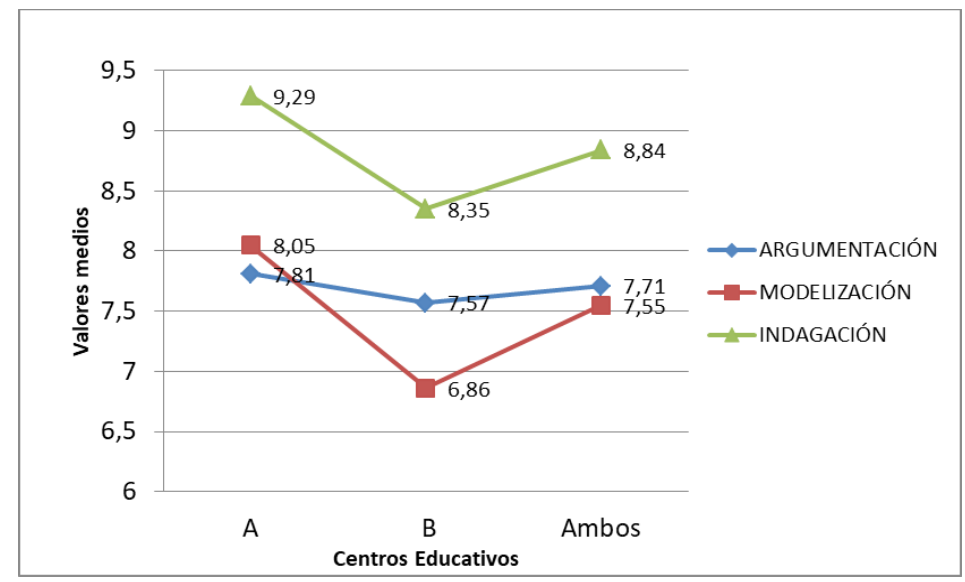

Figura 6. Puntuaciones medias de cada práctica a partir de las fichas de valoración

Durante el desarrollo de la SEA y mediante las fichas de valoración los alumnos manifestaron 
estas tendencias. Los siguientes comentarios realizados en las sesiones de indagación ilustran su preferencia por esta práctica, resaltando aspectos tanto del diseño del yogur como de su elaboración en el laboratorio y de su evaluación:

"Lo mejor de la clase fue diseñar el propio yogur" (B10)

"Lo mejor ha sido los experimentos para elaborar yogur" (A04)

"Lo mejor ha sido saber las propiedades y variables del yogur" (A06)

Del mismo modo, algunos alumnos también valoraron que la indagación permitía mejorar su diseño experimental:

"Los yogures me salieron mal, pero puedo hacerlos de nuevo" (B06)

"La alumna E04B me indicó que ya sabía por qué le había salido mal un yogur: había olvidado echar una cucharada de yogur" (Diario profesor B)

"Algunos alumnos proponen poner en una yogurtera las mezclas del frigorífico que no han salido" (Diario profesor B).

Cabe resaltar que en las tareas de indagación se encontró la respuesta mayoritaria "nada" al valorar lo peor de la sesión, indicativa de que esta práctica fue de su agrado, probablemente por tratarse de la única práctica donde tuvieron la oportunidad de realizar actividades experimentales. Asimismo, los profesores detectaron este interés hacia estas tareas, que registraron como sigue en su diario de observación:

"Lo que parece haber funcionado mejor de la actividad ha sido la predisposición inicial que traían los alumnos para llevar a la práctica su diseño de yogur” (Diario profesor A)

"A algunos les llamó la atención que sus yogures no hubiesen salido, su textura, que tuviera mucho líquido, y sin embargo que el de otros compañeros tuviera forma de yogur" (Diario profesor B)

Los estudiantes valoraron la naturaleza de las tareas de argumentación al permitirles "contrastar diferentes puntos de vista" (B04) o "poder reflexionar juntos" (A02). Los profesores también recogieron algunas reflexiones en torno a estas tareas como: "Los alumnos mantuvieron la atención durante toda la hora" (Diario profesor A) o "el interés y el debate se generó en el aula al contrastar opiniones opuestas" (Diario profesor B)

A pesar de que la práctica de modelización fue la menos valorada, algunos estudiantes pusieron de manifiesto sus virtudes en el aprendizaje: "He desarrollado la imaginación haciendo el modelo" (B01), "cada compañero tenía un modelo diferente" (A10) o "coincido con el modelo de otros compañeros" (B09).

De la misma forma, al proponer un modelo mejorado, se ofrecieron algunas ideas importantes al modelizar como: "Es importante conocer los errores de mi primer modelo" (A01), "lo mejor ha sido intentar averiguar un nuevo modelo" (A06), "no importa si te equivocas" (A07) o "te das cuenta de los errores" (A10).

A pesar de estos avances, un número considerable de alumnos apreciaba este tipo de tareas como tediosas y difíciles: "Es una tarea aburrida" (A11), "había que pensar mucho" (A02), "no tenía casi pistas para hacer el modelo" (B11), "lo peor era hacer los dibujos" (B05). Incluso varios estudiantes llegaron a pensar que la actividad era siempre la misma: "Algunas actividades se repetían y tenías que volver a dibujar tus modelos y a escribir tu argumento" (A03). Otros, se apoyaban en que no se trataba de actividades experimentales: "no ha habido práctica" (A06).

Del mismo modo, los profesores reflexionaron sobre el escaso interés mostrado por algunos alumnos ante las tareas de modelización:

'La actividad no engancha a algunos alumnos más allá de crear su propio modelo. 
Durante la puesta en común ciertos alumnos pierden el interés. La creación de un modelo no lo ven con demasiado interés, probablemente porque no le vean una utilidad" (Diario profesor B)

'La puesta en común resulta interesante en el sentido de que la imaginación de los alumnos ha logrado plasmar modelos interesantes (reacción química, dos tipos de bacterias uno como sustrato, digestión, fusión, mezcla...). Sin embargo, no todos los alumnos participan en las discusiones" (Diario profesor A)

Estos resultados también aparecieron en los 58 comentarios realizados por los estudiantes a las actividades que más y menos les había gustado (ítem 6, Anexo II). Destaca el número de comentarios positivos (39/58) que duplican a los negativos (19/58), otro indicio de que la SEA les agradó. La indagación es la práctica científica con mayor aceptación (26/39 de los comentarios positivos) destacándose especialmente las tareas relativas a la elaboración de yogur ("lo que más me gustó fue hacer yogur") y su degustación ("probar yogur"). Entre las tareas que más agradan hay pocas diferencias entre las de argumentación (6/39) y modelización (7/39). Algunos comentarios positivos sobre la argumentación fueron "descubrir si el yogur es necesario o no" o "argumentar a partir de textos de revistas científicas", y para la modelización "crear nuestros propios modelos" o "comparar con los modelos de los compañeros".

Los datos obtenidos en las tareas también muestran que de los 19 comentarios totales sobre lo que menos les gusta, 17 se refieren a las de modelización. Se apoyaban de nuevo en algunas ideas ya detectadas, principalmente en su apreciación de que a lo largo de la SEA habían realizado tareas idénticas (elaborar un modelo inicial e irlo mejorando, hacer dibujos, o reflexionar y argumentar sobre los modelos) expresadas con comentarios como "lo que menos me gustó fue hacer los modelos en varias actividades", "que las actividades eran muy largas" o "había que reflexionar mucho sobre los modelos". Estos aspectos evidencian que no todo el alumnado llegó a entender el objetivo didáctico de las tareas de modelización. Destaca también que sólo 2/19 de los comentarios negativos se referían a la indagación como "buscar información en Internet", y ninguno de ellos a la argumentación.

El análisis de la comparación entre grupos de las valoraciones que hacen los estudiantes de cada uno de los aspectos de las prácticas científicas (Tabla 3) muestran diferencias estadísticamente significativas entre grupos, a favor del grupo A que valoró mejor las tareas 2 (proponer un contraargumento), 4 (construir modelos), 5 y 6 (planificación y diseño de la investigación).

Tabla 3. Estadísticos descriptivos de la prueba de U de Mann-Whitney de las valoraciones de cada tarea

\begin{tabular}{|c|c|c|c|c|}
\hline \multirow[b]{2}{*}{$\begin{array}{l}\text { Práctica } \\
\text { científica }\end{array}$} & \multirow[b]{2}{*}{ Aspectos } & \multirow[b]{2}{*}{ Tarea } & \multicolumn{2}{|c|}{ Diferencia entre grupos } \\
\hline & & & $\mathbf{Z}$ & $\mathrm{p}$ \\
\hline \multirow{3}{*}{ A } & Construir un argumento & 1 & -0.689 & NS \\
\hline & Proponer un contraargumento & 2 & -0.002 & $0.048^{*}$ \\
\hline & Construir un argumento & 14 & -0.001 & NS \\
\hline \multirow{3}{*}{ M } & Construir modelos & 4 & -0.002 & $0.035^{*}$ \\
\hline & Revisar modelos & 9 & -0.001 & NS \\
\hline & Utilizar modelos & $10-11$ & -0.864 & NS \\
\hline \multirow{3}{*}{ I } & Análisis de datos & 3 & -1.489 & NS \\
\hline & $\begin{array}{l}\begin{array}{l}\text { Planificación } \\
\text { investigación }\end{array}\end{array}$ & $5-6$ & -2.277 & $0.023 *$ \\
\hline & Recogida y procesamiento de datos & $7-8$ & -1.302 & NS \\
\hline
\end{tabular}

*A favor del grupo A 
En el análisis de las diferencias entre las valoraciones (global y por centro) otorgadas a cada práctica científica (Tabla 4) se detectaron diferencias significativas a favor de las tareas de indagación frente a las de argumentación y modelización respectivamente, para la muestra global y para el grupo B.

Tabla 4. Estadísticos descriptivos en muestras relacionadas para comparar la suma de las puntuaciones dadas a las tareas en cada práctica científica

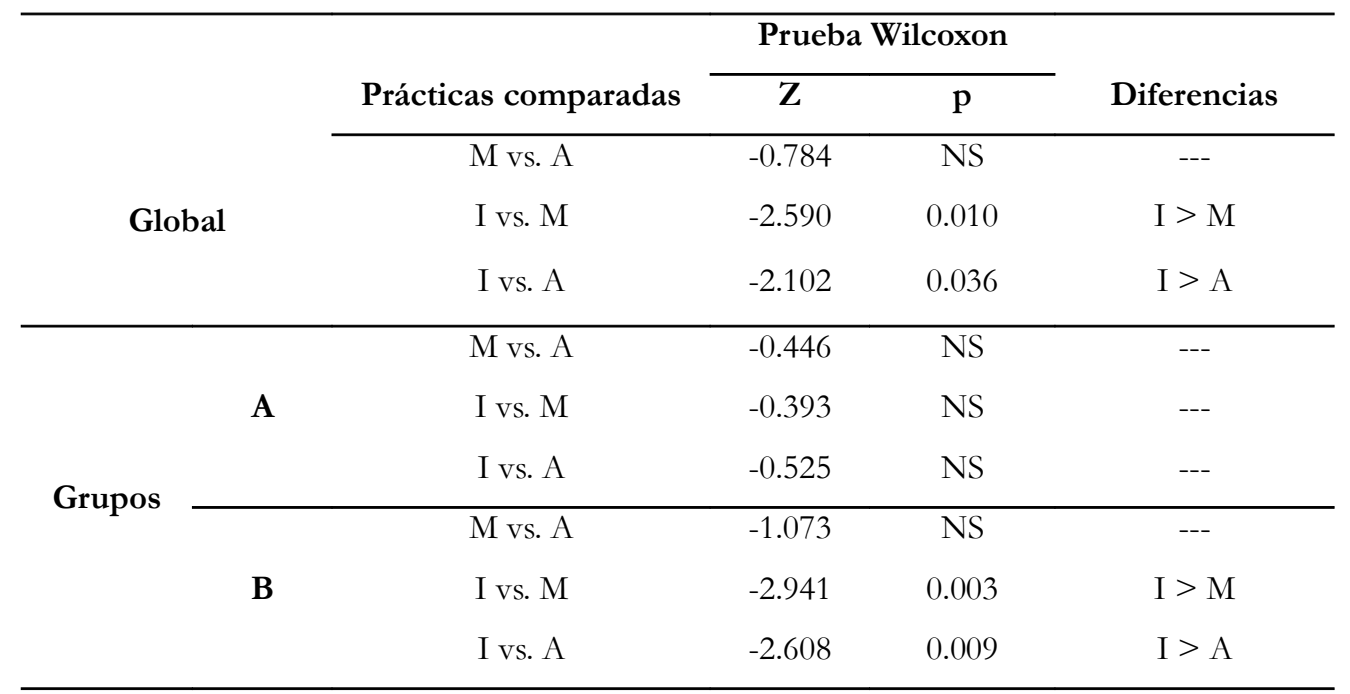

\section{Conclusiones}

Este trabajo analiza las valoraciones que hacen estudiantes de $4^{\circ}$ ESO de dos centros sobre una SEA que integra prácticas científicas AIM en el contexto del consumo de yogur, considerando que estas valoraciones, conjuntamente con las del aprendizaje, constituyen aspectos clave en la evaluaciones de las SEAs. Desde el punto de vista metodológico consideramos que ha sido importante confrontar las valoraciones del alumnado con diferentes instrumentos y en distintos momentos del desarrollo de la SEA, lo que ha permitido una mayor riqueza y variedad en los datos y otorga una mayor validez a los resultados. Cabe resaltar la novedad del uso de fichas de valoración de las tareas inmediatamente después de ser realizadas.

Con respecto a las preguntas de investigación P1 y P3, los resultados muestran que:

- La SEA fue recibida positivamente por el alumnado, percibiéndola 20/25 estudiantes como novedosa y la totalidad de ellos como interesante, y considerando 24 de ellos que habían estado implicados o muy implicados en su desarrollo. Igualmente, la mayoría (16) considera adecuada la forma de trabajo en clase, con la que le gustaría seguir aprendiendo.

- Asimismo, la SEA les ha permitido aprender mucho sobre el tema (18/25) y algo sobre ciencias (18/25). Esta diferencia de percepción solo es estadísticamente significativa en el grupo A, cuyos estudiantes no habían recibido antes formación sobre las prácticas científicas. Parece que el hecho de no recibir, como era habitual para ellos, una enseñanza centrada en los conocimientos científicos "diluye" la percepción que tienen los estudiantes de estar aprendiendo ciencia cuando utilizan un nuevo enfoque (Rodríguez-Mora y Blanco 2015).

Con respecto a las preguntas de investigación P2 y P3, los resultados obtenidos muestran que: 
- Tomando en consideración los elementos de cada una de las prácticas, se aprecian valoraciones similares entre ambos grupos de estudiantes. No obstante, los estudiantes del grupo A valoraron mejor que los del B tres tareas concretas relacionadas con proponer un contraargumento, construir un modelo y planificación y diseño de la investigación.

- En su conjunto las tareas relacionadas con cada práctica científica no fueron percibidas de la misma forma, encontrándose que la indagación es mejor valorada que argumentación y modelización aunque no aparecen diferencias entre estas dos últimas. Estas diferencias globales aparecen solo en el grupo B, lo que puede apoyar la explicación dada anteriormente sobre las diferencias de percepción sobre el aprendizaje.

Estas conclusiones parecen sugerir que para estudiantes que no tienen familiarización con el trabajo de las prácticas científicas, la indagación es la que inicialmente capta mejor su interés, pero una vez finalizada la SEA, el alumnado valora de forma similar tanto indagación como argumentación.

El caso de la modelización parece diferente ya que, en las tareas de aprendizaje aparece como la práctica menos valorada. Quizás es en la práctica en la que la falta de familiarización aparece como un factor más determinante. Parece necesario que el profesorado haga un mayor y más preciso apoyo didáctico para ayudar al alumnado al iniciarse en la modelización (Acher 2014). Los comentarios de los estudiantes apuntan tanto a la dificultad de la modelización en sí misma como a la dificultad para diferenciar los propósitos de las diferentes tareas de modelización (les parecían iguales). El primer tipo de dificultad muestra la necesidad de una iniciación bien secuenciada de dichas tareas (Schwarz et al. 2009) y el segundo tipo la necesidad de combinar tareas de modelización con las de metamodelización (Aragón, Oliva y Navarrete 2014).

Cabe resaltar que este estudio aporta datos, considerados iniciales, que apuntan a que desde la perspectiva del alumnado la reclamada integración de prácticas científicas (Caamaño 2011) es posible dando lugar a SEAs que sean de su interés y en las que se impliquen. También ha aportado datos que posibilitan llevar a cabo mejoras de la SEA evaluada, tanto en su diseño como en la puesta en práctica en el aula.

Aun siendo conscientes de que el número de estudiantes que han participado en el estudio es pequeño, consideramos que los resultados obtenidos permiten su extrapolación ya que se ha realizado en contextos escolares que podemos considerar habituales en cuanto a las características de los estudiantes de $4^{\circ}$ ESO que han elegido la asignatura de Física y Química, y su escasa familiaridad con la utilización de las prácticas científicas en las clases de ciencias (OECD 2016). Esto no implica que su utilización con otros estudiantes no requiera de las necesarias acciones de adaptación a sus contextos educativos. Queda pendiente conocer cómo recibirían y, en su caso, llevarían a la práctica esta SEA otro profesorado que no haya estado implicado en su diseño, constituyendo esta transferencia otro aspecto importante de su evaluación (Leach y Scott 2002).

\section{Agradecimientos}

Este trabajo es parte del proyecto de I+D de Excelencia EDU2017-82197-P, financiado por el Ministerio de Economía, Industria y Competitividad en 2017.

\section{Referencias}

Acher, A. (2014). Cómo facilitar la modelización científica en el aula. Tecné Episteme y Didaxis, $36,63-75$. 
Aragón, M.M., Oliva, J.M. \& Navarrete, A. (2014). Desarrollando la competencia de modelización mediante el uso y aplicación de analogías en torno al cambio químico. Enseñanza de las Ciencias, 32(3), 337-356.

Barrow, L.H. (2006). A brief history of inquiry: from Dewey to Standards. Journal of Science Teacher Education, 17, 265-278.

Bevins, S. \& Price, G. (2016) Reconceptualising inquiry in science education. International Journal of Science Education, 38(1), 17-29.

Blanco, A., España, E., Franco-Mariscal, A.J. \& Rodríguez, F. (2018). Competencias prácticas científicas en problemas de la vida diaria. Alambique, Didáctica de las Ciencias Experimentales, 92, 45-51.

Bybee, R.W. (2006). Scientific inquiry and science teaching. In L.B. Flick \& N. G. Lederman (Eds.), Scientific inquiry and nature of science, (pp. 1-14). Dordrecht: Springer.

Caamaño, A. (2005). Presentación de la monografía: Contextualizar la ciencia. Una necesidad en el nuevo currículo de ciencias. Alambique, Didáctica de las Ciencias Experimentales, 46, $5-8$.

Caamaño, A. (2011). Enseñar química mediante la contextualización, la indigación y la modelización. Alambique, Didáctica de las Ciencias Experimentales, 69, 21-34.

Chamizo, J. \& Izquierdo, M. (2005). Ciencia en contexto: una reflexión desde la filosofía. Alambique, Didáctica de las Ciencias Experimentales, 46, 9-17.

Cohen, L., Manion, L. \& Morrison, K. (Eds.) (2007). Research Methods in Education. New York: Routledge.

Couso, D. (2011). Las secuencias didácticas en la enseñanza y el aprendizaje de las ciencias: modelos para su diseño y validación. En Caamaño, A. (Ed.), Didáctica de la física y la química, (pp. 57-84). Barcelona: Graó.

Duit, R. (2006). La investigación sobre enseñanza de las ciencias. Un requisito imprescindible para mejorar la práctica educativa. Revista Mexicana de Investigación Educativa, 11(30), 741770 .

Duschl, R.A. \& Osborne, J. (2002). Supporting and promoting argumentation discourse in science education. Studies in Science Education, 38(1), 39-72.

Erduran, S. \& Jiménez-Aleixandre, M.P. (Eds.) (2008). Argumentation in science education: perspectives from classroom-based research. Dordrecht: Springer.

España, E. \& Prieto, T. (2009). Educar para la sostenibilidad: el contexto de los problemas socio-científicos. Revista Eureka sobre Enseñanza y Divulgación de las Ciencias, 6(3), 345354.

Fensham, P. (2009). Real world contexts in PISA science: implications for context-based science education. Journal of Research in Science Teaching, 46(8), 884-896.

Franco-Mariscal, A.J. (2015). Competencias científicas en la enseñanza y el aprendizaje por investigación. Un estudio de caso sobre corrosión de metales en secundaria. Enseñanz̧a de las Ciencias, 33(2), 231-252.

Freire, S., Faria, C., Galvao, C. \& Reis, P. (2013). New curricular material for science classes: How do students evaluate it? Research in Science Education, 43(1), 163-178.

Gilbert, J.K. (2006). On the nature of context in chemical education. International Journal of 
Science Education, 28(9), 957-976.

Gilbert, J.K. \& Justi, R. (2016). Models and Modeling in Science Education. Switzerland: Springer.

Hodson, D. (2014). Learning Science, Learning about Science, Doing Science: Different goals demand different learning methods. International Journal of Science Education, 36(15), 2534-2553.

Jiménez-Aleixandre, M.P. (2002). Knowledge producer sor knowledge consumers? Argumentation and decision making about environmental management. International Journal of Science Education, 24(11), 1171-1190.

Jiménez-Aleixandre, M.P. (2010). Competencias en argumentación y uso de pruebas. 10 ideas clave. Barcelona: Graó.

Jiménez-Liso, M.R., López-Gay, R. \& Márquez, M.M. (2010). Química y cocina: del contexto a la construcción de modelos. Alambique, Didáctica de las Ciencias Experimentales, 65, 33-44.

Justi, R. (2006). La enseñanza de ciencias basada en la elaboración de modelos. Enseñanza de las Ciencias, 24, 173-184.

King, D. \& Ritchie, S. (2012). Learning science through real world contexts. In B. Fraser, K. Tobin \& C. McRobbie (Eds.), Second International Handbook of Science Education, (pp. 6977). Dordrecht, NL: Springer.

Leach, J. \& Scott, P. (2002). Designing and evaluating science teaching sequences: an approach drawing upon the concept of learning demand and a social constructivist perspective on learning. Studies in Science Education, 38(1), 115-142.

Martin-Hansen, L. (2002). Defining inquiry. The Science Teacher, 69(2), 34-37.

Méheut, M. \& Psillos, D. (2004). Teaching-learning sequences: aims and tools for science education research. International Journal of Science Education, 26(5), 515-535.

Moreno, G., \& López, A. (2013). Construcción de modelos en clase acerca del fenómeno de la fermentación, con alumnos de educación secundaria. Revista Latinoamericana de Estudios Educativos (Colombia), 9(1), 53-78.

Muñoz-Campos, V., Blanco, A. \& Franco-Mariscal, A.J. (2015). La elaboración de yogur como contexto para el aprendizaje de la reacción química mediante modelización. En P. Membiela, N. Casado y M.I. Cebreiros (Eds.), La enseñanza de las ciencias: desafíos y perspectivas, 43, pp. 265-269. Ourense: Educación Editora.

NRC, National Research Council. (2012). A Framework for K-12 science education: Practices crosscutting concepts, and core ideas. Washington, DC: National Academy Press.

OECD (2016). 2015 Results (Volume II): Policies and practices for successful schools. Paris: OECD Publishing. http://dx.doi.org/10.1787/9789264267510-en

Oliva, J.M. (2019). Distintas acepciones para la idea de modelización en la enseñanza de las ciencias. Enseñanza de las Ciencias, 37(2), 5-24.

Osborne, J.F., Henderson, J.B., MacPherson, A., Szu, E., Wild, A. \& Yao, S. (2016). The development and validation of a learning progression for argumentation in science. Journal of Research in Science Teaching, 53(6), 821-846.

Psillos, D. \& Kariotoglou, P. (2016). Theoretical issues related to designing and developing teaching-learning sequences. In D. Psillos \& P. Kariotoglou (Eds.), Iterative design of teaching-learning sequences, (pp. 11-34). Dordrecht: Springer. 
Rodríguez-Mora, F. \& Blanco, A. (2015). ¿Por qué bebemos agua embotellada? Una propuesta para la enseñanza de la Física y Química en $3^{\circ}$ de ESO. En A. Blanco-López y T. Lupión Cobos (Eds.), La competencia científica en las aulas. Nueve propuestas didácticas, (pp. 207-246). Santiago de Compostela: Andavira.

Rönnebeck, S., Bernholt, S. \& Ropohl, M. (2016). Searching for a common ground - A literature review of empirical research on scientific inquiry activities. Studies in Science Education, 52(2), 161-197.

Sanmartí, N. (coord.) (2003). Aprendre ciències tot aprenent a escriure ciència. Barcelona: Edicions 62

Schwarz, C. (2009). Developing preservice elementary teachers' knowledge and practices through modeling-centered scientific inquiry. Science Education, 93(4), 720-744.

Schwarz, C.V., Reiser, B.J., Davis, E.A., Kenyon, L., Acher, A., Fortus, D. \& Krajcik, J. (2009). Developing a learning progression for scientific modeling: Making scientific modeling accessible and meaningful for learners. Journal of Research in Science Teaching, 46, 632654.

Toulmin, S.E. (2003). The uses of argument ( $3^{\text {rd }}$ edition). Cambridge: Cambridge University Press. 
Anexo I. Ficha de valoración de las tareas (instrumento 1)

FICHA DE VALORACIÓN DE LA ACTIVIDAD

Nombre:

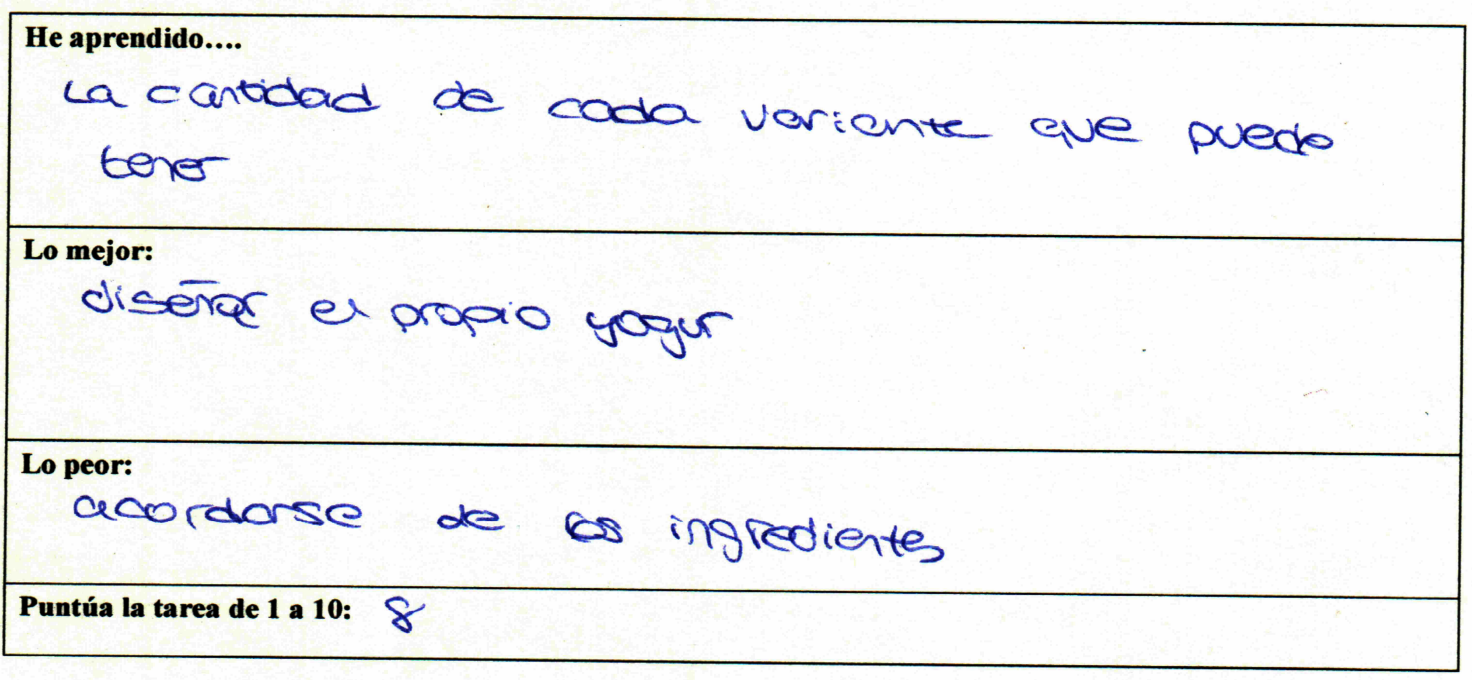




\section{Anexo II. Cuestionario de evaluación de la experiencia (instrumento 2)}

$\square$ Chico

$\square$ Chica

Responde, por favor, de forma sincera a estas preguntas. Señala la opción que esté más de acuerdo con tu percepción.

1. La forma en que se ha trabajado en las clases durante la SEA "¿es necesario tomar yogur?" ha sido:

$\square$ Prácticamente igual a la de siempre

$\square$ Han cambiado algunas cosas (actividades, forma de relacionarnos en las clases, actuación de profesor, ...), pero la mayoría han sido similares

$\square$ Han cambiado muchas cosas

$\square$ Ha sido totalmente nueva

Observaciones

2. El tema que se ha tratado en la SEA te ha parecido:
$\square$ Muy poco interesante
$\square$ Poco interesante
$\square$ Interesante
$\square$ Muy interesante

Observaciones

3. En general, durante esta SEA en las clases te has sentido:

$\square$ Muy poco implicado/a $\square$ Poco implicado/a $\square$ Implicado/a $\square$ Muy implicado/a Observaciones

4. Sobre el tema tratado has aprendido:
$\square$ Muy poco
$\square$ Poco
$\square$ Algo
$\square$ Mucho

Observaciones

5. En general, durante esta SEA, sobre ciencia has aprendido:
$\square$ Muy poco
$\square$ Poco
$\square$ Algo
$\square$ Mucho

Observaciones

6. Indica las actividades que más te han gustado y las que menos de esta SEA:

\begin{tabular}{|l|l|}
\hline Lo que más me ha gustado & Lo que menos me ha gustado \\
\hline & \\
\hline
\end{tabular}

7. ¿Te gustaría que la forma de trabajar en las clases de esta asignatura fuese siempre tal y como se ha hecho en esta SEA?
$\square$ Sí
$\square$ No
$\square$ Depende

Razona tu respuesta

8. ¿Cuándo has aprendido más: en esta SEA o en las anteriores que se han dado en esta asignatura? Razona tu respuesta 